\title{
Spatial extent of precipitation events: when big is getting bigger
}

\author{
Dominic Matte ${ }^{1,2}$ (J) Jens H. Christensen ${ }^{1,4} \cdot$ Tugba Ozturk $^{1,3}$ \\ Received: 10 September 2020 / Accepted: 6 October 2021 / Published online: 21 October 2021 \\ (c) The Author(s) 2021
}

\begin{abstract}
Using a sub-selection of regional climate models at $0.11^{\circ}(\approx 12 \mathrm{~km})$ grid resolution from the EURO-CORDEX ensemble, we investigate how the spatial extent of areas associated with the most intensive daily precipitation events changes as a consequence of global warming. We address this by analysing three different warming levels: $1{ }^{\circ} \mathrm{C}, 2{ }^{\circ} \mathrm{C}$ and $3{ }^{\circ} \mathrm{C}$. We find that not only does the intensity of such events increase, but their size will also change as a function of the warming: larger systems becomes more frequent and larger, while systems of lesser extent are reduced in numbers.
\end{abstract}

Keywords Extreme precipitation $\cdot$ Regional climate model $\cdot$ EURO-CORDEX $\cdot$ Spatial extent of precipitation

\section{Introduction}

Extreme precipitation leading to flooding is undoubtedly one of the most damaging and costly climate hazards (Ahern et al. 2005; Knapp et al. 2008; Woetmann 2011; Hallegatte et al. 2013; Liu et al. 2016; Masson-Delmotte et al. 2018). For an extreme precipitation event to become damaging, several aspects have to be considered, e.g. the location; the timing; rural land vs densely populated; dry, wet or frozen grounds; catchment size and topography; tides and storm surges, etc. (Westra et al. 2014; Woetmann 2011; Liu et al. 2016). One or a combination of several of those aspects could play a major role in the severity of the experienced disaster.

In the last decades, the mechanisms leading to extreme precipitation and the impact of climate change on such event have been the main interest of many studies (Frei et al. 1998; Trenberth et al. 2003; Christensen and Christensen 2007; O'Gorman and Schneider 2009; Prein et al. 2015, 2017a,

Dominic Matte

matte.dominic@ouranos.ca

1 Present Address: Physics of Ice, Climate and Earth, Niels Bohr Institute, University of Copenhagen, Copenhagen, Denmark

2 Ouranos, 550 Rue Sherbrooke W., West Tower, 19th Floor, Montréal, QC H3A 1B9, Canada

3 Department of Physics, Faculty of Arts and Sciences, Isik University, 34980 Istanbul, Turkey

4 NORCE Norwegian Research Centre AS, Bergen, Norway b; Púčik et al. 2017; Chan et al. 2018; Marelle et al. 2018; Tramblay and Somot 2018). Despite these many studies on the subject, the changing characteristics of future extreme precipitation events have still not fully been explored and understood. To establish a detailed picture of the spatial and temporal response of precipitation extremes to a warmer climate, several aspects should be considered and correctly understood such as: (1) the frequency (Frei et al. 1998), (2) the intensity (Frei et al. 1998; Christensen and Christensen 2007; Prein et al. 2017a, b), (3) the seasonality (Marelle et al. 2018; Brönnimann et al. 2018), (4) the diurnal timing (Scaff et al. 2019) and (5) the size (Berg et al. 2013; Guinard et al. 2015; Wasko et al. 2016; Chang et al. 2016; Lochbihler et al. 2017; Prein et al. 2017a; Benestad 2018; Touma et al. 2018).

Overall, for Europe, extreme precipitation is expected to increase in frequency and intensity (Christensen and Christensen 2003, 2007; Rajczak and Schär 2017; Chan et al. 2018; Tramblay and Somot 2018). For some regions, medium-to-strong precipitation events, which potentially become hazardous, are highly dependent on the time of occurrence during the year. Although high-impact extreme precipitation events are expected to mostly occur in summer when convection is the predominant mechanism, it may also occur in winter but for different reasons. Marelle et al. (2018) suggest that extreme events might shift from summer to early fall for some regions (including Europe and particularly stronger in the northern part of Europe).

From the Clausius Clapeyron (C-C) relationship, an increase in atmospheric moisture content by approximately 
$6-7 \% /{ }^{\circ} \mathrm{C}$ is expected and so extreme precipitation should increase in a similar manner (Trenberth et al. 2003). This has to some extent been identified in observations as well as in model simulations (Prein et al. 2015, 2017b; Liu et al. 2016). Berg et al. (2013) even found that the more intensive precipitation, e.g. the 99th percentile of daily precipitation, seems to follow a super $\mathrm{C}-\mathrm{C}$ rate $\left(14 \% /{ }^{\circ} \mathrm{C}\right)$, while a lower percentile (75th) follows the regular $\mathrm{C}-\mathrm{C}$ rate $\left(7 \% /{ }^{\circ} \mathrm{C}\right)$. Such changes in the precipitation characteristics implies a profound impact over the entire hydrological cycle. Chang et al. (2016) suggested that mechanisms are taking place compensating for the imbalance between the increase of intensity of the individual precipitation event of $6-7 \% /{ }^{\circ} \mathrm{C}$ with the total global average $\left(1-2 \% /{ }^{\circ} \mathrm{C}\right)$ precipitation rate increase. Those mechanisms could be either (1) thermodynamic: affecting the redistribution of the additional humidity within the precipitation system or (2) dynamical: affecting the system cell organization. However, the identification of those mechanisms is subject to physical caracteristic changes such as the starting location, the intensity, the spatial extent, the duration and the trajectory of the precipitation system (Chang et al. 2016) while being also sensitive to the available moisture and region in concern. Such compensating mechanisms are likely to impact the size of future precipitation systems, especially for the most intensive precipitation events.

Until now, few studies (e.g. Berg et al. 2013; Guinard et al. 2015; Wasko et al. 2016; Chang et al. 2016; Lochbihler et al. 2017; Prein et al. 2017a; Benestad 2018; Touma et al. 2018) have considered changes in the size of the geographical area impacted by precipitation events. Amongst those studies, some suggest an increase while others find a decrease. Prein et al. (2017a) for example, tracked mesoscale convective systems in the US. Their analysis shows that the area receiving rain from a particular event is expected to increase by $20-70 \%$ in a warmer climate. Using gauged precipitation records, Berg et al. (2013) showed that spatially extended precipitation events size (i.e. stratiform) is increasing while the mean precipitation per square kilometer is decreasing with warmer temperature. However, for convective systems both the mean amount and the size of the systems increases. Along with those results, Lochbihler et al. (2017) used 9 years of summertime rain radar data to show that size increases when dew point temperatures are above $15^{\circ} \mathrm{C}$.

On the other hand, several studies have suggested an opposite trend to the spatial extent. For example, Wasko et al. (2016) used observations provided by the Australian Bureau of Meteorology to build a relationship between temperature and various statistics describing the organization of moisture within extreme storms selected, adopting a 90th percentile precipitation threshold. They concluded that intensity is increasing, while spatial extent decreases with warmer temperature. Chang et al. (2016) came to a similar conclusion using a $12-\mathrm{km}$ grid regional model simulation over a region covering the continental United States. Using a rainstorm-tracking algorithm, they showed that rainstorm size will decrease in a warmer future while the intensity increases. However, those changes becomes uncertain due to models biases in the present-day simulation (as compared to observations) being stronger than the climate change signal.

In contrast, Guinard et al. (2015) found no climate change related signal in precipitation area (investigating all precipitation systems) using the Canadian Regional Climate Model over the North American continent. Finally, Benestad (2018) suggested that the spatial extent of daily precipitation episodes has decreased in the last decade leading to a more intense localized precipitation. According to the same study, end-of-century climate projections show a considerable decrease of the spatial extent of up to $28 \%$ for the daily precipitation events responsible for intense but identifiable as smaller systems.

These contradictory findings are not only a result of the adopted approaches and definitions used for computing the spatial extent of precipitation systems, but also of the uncertainties related to model differences. They strongly suggest that a stronger and better general understanding of the changes in size of the area experiencing precipitation is needed.

In this study, our goal is to try to shed additional light on this issue using a multimodel approach, to investigate the changes in size of the adjacent areas influenced by precipitation located around a 20 -years extreme daily precipitation events for three specific warmer climate states. To do so, we use an ensemble of 19 members from the $0.11^{\circ}$ EUROCORDEX dataset using different warming levels of $1{ }^{\circ} \mathrm{C}$, $2{ }^{\circ} \mathrm{C}$ and $3{ }^{\circ} \mathrm{C}$, respectively, compared to the reference period 1986-2005. The paper is organized as follows: in the next section we describe the simulation data and the metric used to produce the analysis. Section 3 shows the overall simulated size distribution from regional climate model (RCM) together with ERA5 (Hersbach et al. 2020) highlighted by our approach; followed by Sect. 4 where results of climate change analyses are shown. Finally we discuss the results and make concluding remarks in Sect. 5.

\section{Data and methods}

Here, we use the daily pre cipitation from regional climate model simulations produced within the framework of the European Coordinated Regional Climate Downscaling Experiment (hereinafter EURO-CORDEX, Jacob et al. 2014). Figure 1 shows the EURO-CORDEX domain and the sub-domains used in this study. Note that region 6 differs 
Fig. 1 Simulated EURO-CORDEX domain showing the eight sub-regions

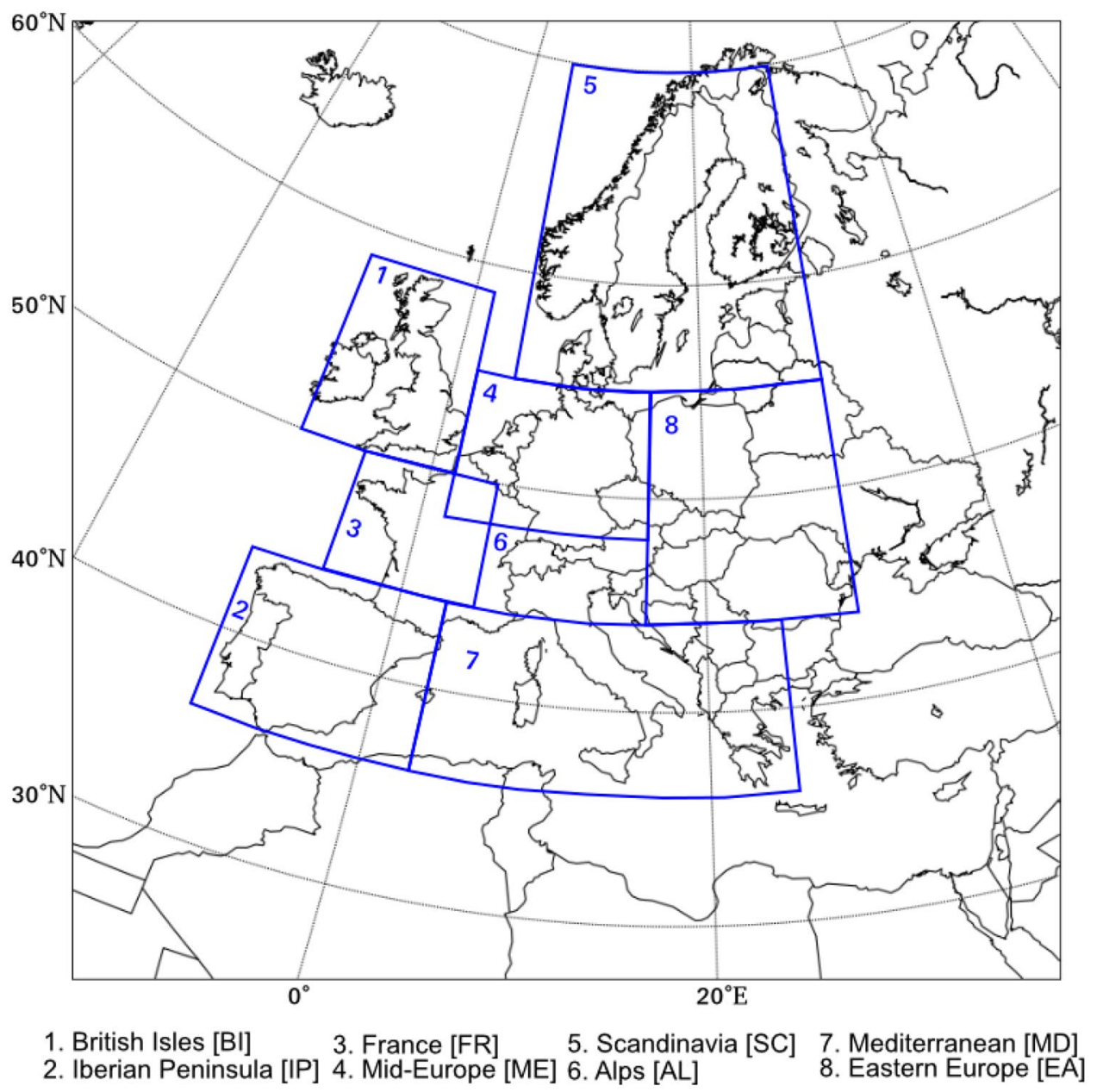

- 1 realisation 3 realisations

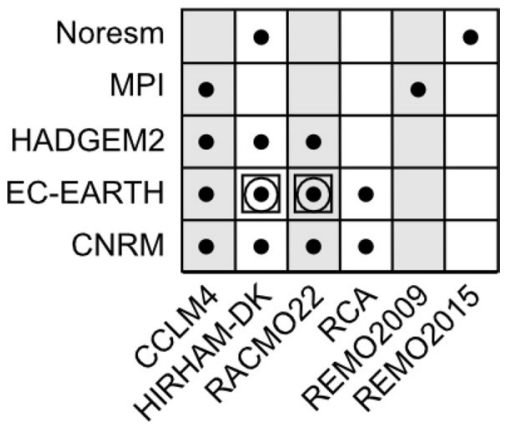

Fig. 2 GCM-RCM matrix

slightly from the original region e.g. presented in Christensen and Christensen (2007).

\subsection{EURO-CORDEX dataset}

In total, 6 RCMs (Fig. 2) driven by 5 GCMs (Fig. 3) together with present-day simulations using ERA-Interim (Simmons et al. 2006) as driving data have been used in this study producing 19 climate projections on a $0.11^{\circ}$ grid-mesh. The historical and the climate projections are using several GCMs as driving data following the representative concentration pathway (RCP) 8.5 scenario (Moss et al. 2010) from 2006 and onwards. The same analysis have been done for the reference period (1989-2008) using ERA5. Simulated daily precipitation results were interpolated using a conservative procedure to the ERA5 grid for the analysis in Sect. 3. Otherwise, the original grid is used for Sect. 4.

In this study, an approach using different warming levels is adopted. We are using the 1986-2005 as a reference period which we are comparing with 3 future periods. For all GCM-RCM combination, the GCM global running mean temperature change is computed over 20 years for each year compared to reference period until the end of the century (e.g. 1987-2006, 1988-2007..and so forth). The 


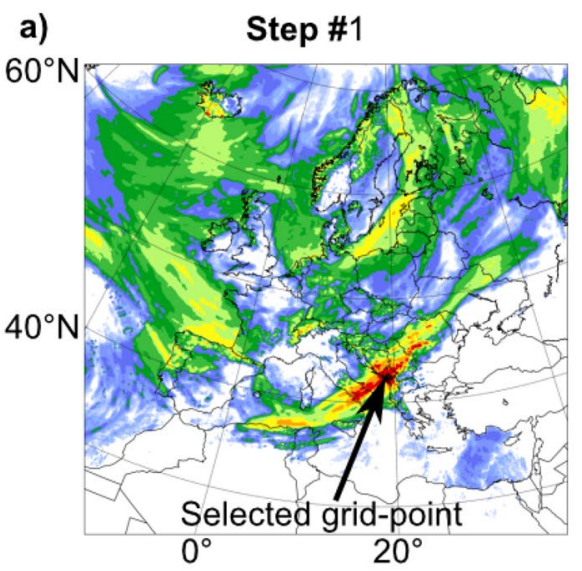

c)

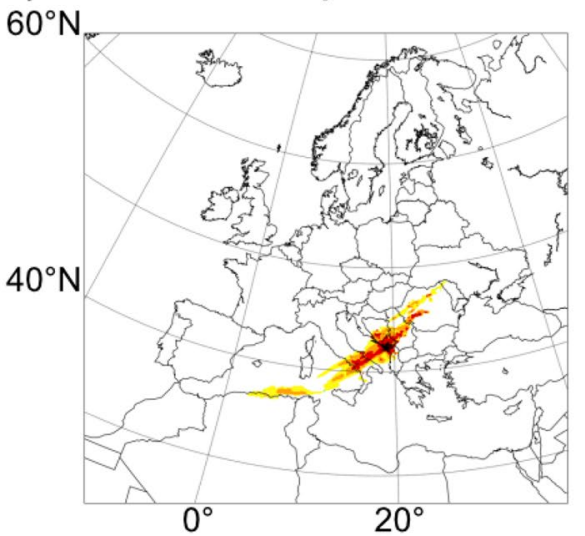

b)

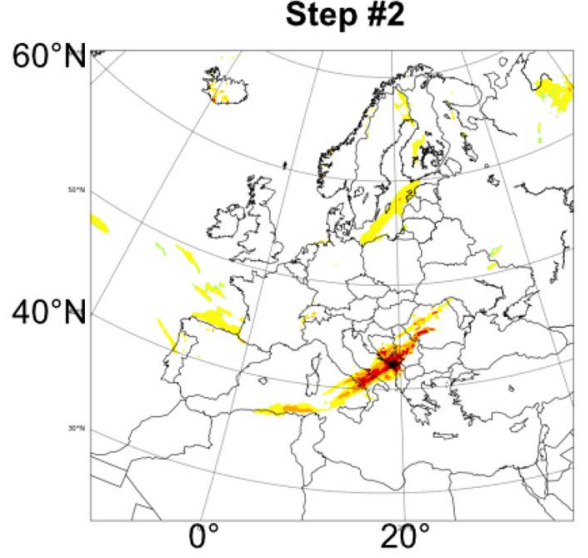

d)

Step \#4

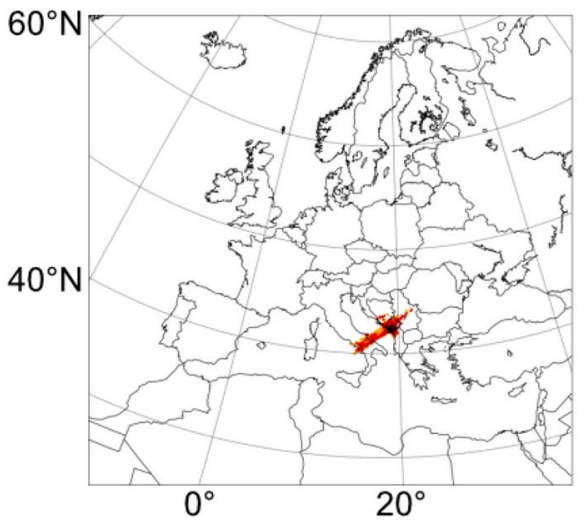

128

32

8

2 हो

0.5

0.125

Fig. 3 Protocol representing one iteration for one grid point for one member for computing 20y-size and 20y-mean for one selected period (in this example the reference period of 1986-2005 is selected)

20-year period when the average global mean temperature change reach $1{ }^{\circ} \mathrm{C}, 2{ }^{\circ} \mathrm{C}$ and $3{ }^{\circ} \mathrm{C}$ of warming, respectively are used to represent warming levels of $1{ }^{\circ} \mathrm{C}, 2^{\circ} \mathrm{C}$ and $3{ }^{\circ} \mathrm{C}$. For example, if the GCM\#1 reached a global average temperature change of $1{ }^{\circ} \mathrm{C}$ for the 2023-2042 period, then 2023-2042 will be the time period where we look for the maximum precipitation over 20 years for the level of 1 ${ }^{\circ} \mathrm{C}$ of each RCM driven by GCM\#1.

\subsection{Selection and computation of system size related to extreme precipitation}

There are no existing formal procedures to delineate the area influenced from a particular localised 20 years extreme precipitation event. To achieve this, we therefore need to provide our own definition. Although identifying an event might not be an issue in itself, assigning an area under influence related to the event at any grid point could be quite challenging. Our approach is further complicated by the fact that we are considering daily extreme precipitation rather than a flash flood event characterize by an hourly time scale.
In this study, the term size is not necessarily related to a coherent weather system or physically connected convection cells but defines an area experiencing precipitation over the course of the $24 \mathrm{~h}$ period between 0 and 24 UTC. In principle, this could also consist of multiple separate systems/ cells passing. This means that the full area we identify may not have seen the same kind of intensive precipitation at any time within $24 \mathrm{~h}$ everywhere, while the most intensive part very well may have been established over a shorter time scale. For example, high $24 \mathrm{~h}$ precipitation amounts in the most extreme cases can be the result of either continuous relatively intense precipitation for $24 \mathrm{~h}$ or be due to a cloud burst of short duration (e.g. even less than $1 \mathrm{~h}$ ). Our approach does not offer any distinction. It is also worth mentioning that no distinction has been made between precipitation type (e.g. liquid or solid, convective, stratiform or orographic).

There are multiple approaches to define and identify the spatial extent of precipitation areas. In this study we apply a percentile threshold to identify a precipitation event at a grid point and then search for connected grid points in the local vicinity that also have precipitation above the threshold. 
Selecting such a threshold is a delicate task since a too small threshold will raise the chance that many or all systems will be interconnected and we will then identify only one very large event while a too large threshold, on the other hand, will only offer the identification of a small fraction of what could form the full event. Hence, a threshold that could be applicable for different datasets and represent its overall spatial distribution of daily precipitation is needed. Models are different, some are systematically dryer and some are wetter than both observations and the bulk of other models, therefore such differences must be handled by the method as well. Since our goal is to assess any potential change in size-characteristics under climate change and not systematic model errors, the threshold should be defined accordingly and be applicable for each dataset. The percentiles should be computed from a representative distribution of daily precipitation and in the following we describe the procedure in detail.

First: we selected a random inland grid point and extracted a daily precipitation map for the whole domain on the day where the 20-years extreme precipitation occurred at that grid point. Second: we excluded all grid points with a value of less than a $1 \mathrm{~mm} /$ day from further analyses. Third: we repeated this operation for another random inland grid point where we pool the values to the values from the first selected grid point. This operation was repeated another 498 times (to obtain a total of 500 samples). Fourth: the resulting pooled data sample is then used to determine 90thand 99th percentile precipitation value. This operation is applied to all hindcast (models nested in re-analyses boundaries) simulations and the ERA5 dataset in Sect. 3.

In Sect. 4, the operation is applied only on the historical simulations and the resulting 90th and 99th are then used for both historic and future climate periods. During this process, we make sure that a day was selected only once, even if two or more neighboring grid points had their 20-year extreme precipitation event on that same day. We also consider it to be a plausible but rare case to select the same day twice due to far-distanced regions having their 20-years extreme precipitation on that same day. To address this issue, this operation was repeated multiple times with a negligible impact on the identified values of the 90th and 99th percentiles (not shown). Other methods such as using the local (i.e. gridpoint percentile over the whole period) were also considered. This latter approach was discarded since some areas (such as mountainous and coastal regions) have quite high 90th and 99th percentile values. We direct the reader to the Appendix for a more detailed discussion on the issue of selecting an appropriate threshold for daily precipitation.

We wish to estimate the size and overall system mean precipitation associated with the maximum $24 \mathrm{~h}$ precipitation amount event (occurring between 0 and 24 UTC) within a particular 20-year period (hereafter 20y-size and 20y-mean, respectively). The following steps were considered for each RCM and each of the four selected 20-year periods (see also Fig. 3) and repeated for all land model points:

Step\#1 (Fig. 3a): For any land grid point within the model domain or for a subdomain of interest (a grid point near the Adriatic Sea is chosen as an example) the 20-year time series of daily precipitation data is extracted to identify the day of occurrence of the maximum precipitation over the whole period. Note that just as was the case with the calculation of the percentiles if neighboring grid points had their 20-year extreme precipitation event on the same day, an event was selected only once to avoid double counting.

Step\#2 (Fig. 3b): The full precipitation map of that day is extracted and all grid points with values below the 90th percentile calculated, as described above, were masked out.

Step\#3 (Fig. 3c): We then apply an island detection algorithm (see e.g. https://www.geeksforgeeks.org/find-number-of-islands, consulted on December 2019) on the system connected to the selected grid point to calculate the $20 \mathrm{y}$-size and the $20 \mathrm{y}$-mean by the system delineated by the 90 th percentile (here and after called $20 \mathrm{y}$-size [90th] and 20y-mean[90th]). In Fig. 3c the 20y-size[90th] consists of $\approx 2400$ grid points, which corresponds to $\approx 266$ $000 \mathrm{~km}^{2}$ and the resulting $20 \mathrm{y}$-mean[90th] is $\approx 40 \mathrm{~mm}$.

Step\#4 (Fig. 3d): The following step is to also mask out all value below the 99th percentile and apply the island detection algorithm again to calculate the 20y-size and the $20 y-m e a n$ delineated by the 99 th percentile (here and after the 20y-size[99th] and 20y-mean[99th], resp.). In this example, the $20 y$-size[99th] consists of $\approx 600$ grid points equivalent to $\approx 67000 \mathrm{~km}^{2}$ and the $20 \mathrm{y}$-mean[99th] is $\approx 80 \mathrm{~mm}$.

Given the many odd shapes and sizes such events represent, we define a length scale (L) associated with these events defined by the square root of their area (e.g. in Fig. $3, \mathrm{~L}^{2}=515^{2}$ and $\mathrm{L}^{2}=259^{2} \mathrm{~km}^{2}$ for the $20 \mathrm{y}$-size[90th] and 20y-size[99th], respectively). We have defined discrete size categories using multiples of 2 . Our definition of a small-size system is defined by systems smaller than $128^{2}$ $\mathrm{km}^{2}$, medium-size systems range from $128^{2}$ to $512^{2} \mathrm{~km}^{2}$ and large-size systems are larger than $512^{2} \mathrm{~km}^{2}$.

In the climate change analysis, this set of steps is repeated for each warming level for each model. We should underline a critical point. The two thresholds used are based on the reference periods (of 1989-2008 for Sect.3 and 1986-2005 for Sect.4) for the particular member in concern in order to evaluate changes with respect to this period. 


\section{Present-day size distribution}

\subsection{Size and overall system mean precipitation associated with the most extreme $24 \mathrm{~h}$ precipitation event}

Since we have a priori no idea what to expect about the shape of the size distribution, we performed a sanity check against dataset having similar spatial and temporal resolution and coverage as the ERA5 reanalysis. For example, we have explored other observational datasets such as the E-OBS observational dataset (Cornes et al. 2018), but it was discarded since E-OBS represents land observations only and our approach needs value over the sea as well. That being said, two recent studies (Nogueira 2020; Rivoire et al. 2021) have compared ERA5 with several observational datasets and the previous reanalysis ERA-Interim (e.g. Simmons et al. 2006). Both studies suggest ERA5 shows an overall improvement compared to ERA-Interim (while still being of a rather coarse resolution of $\approx 30 \mathrm{~km}$ grid mesh) and an overall good agreement with observation-based records, which suggests that it may be a useful dataset for an overall quality check. In this section, all EURO-CORDEX simulated results are driven by ERA-Interim. Note that for Fig. 4, Figs. S1 and S2 the simulated daily precipitation data has been conservatively interpolated to the ERA5 grid before applying the procedure described in Sect. 2.2 to both ERA5 and RCMs.

Figure 4a shows the number of events for 20y-size[90th] and directly below (as shown by the downward arrows on Fig. 4c) the value of the 20y-size[99th] conditionned to a $20 y$-size[90th] event. For example, ERA5 shows 1250 events of large size-systems of 20y-size[90th](black bar

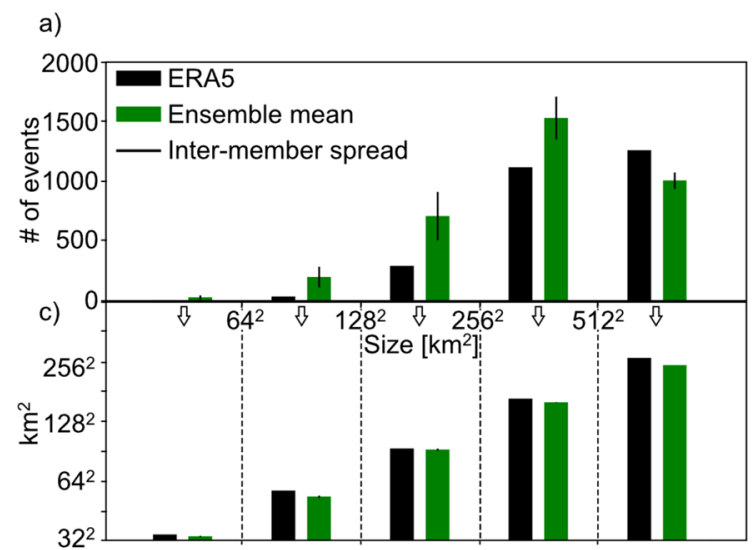

Fig. 4 Present-day size distribution results for ERA5 (black), the ensemble mean (green) and the inter-model spread (black lines) for the 1986-2005 period over the whole EURO-CORDEX domain. Panel a shows of the number of events for 20y-size[90th]; panel of the last bin of Fig. 4a). The average size of their more intense core, 20y-size[99th], is a bit larger than $256 \times 256$ $(\approx 65,000) \mathrm{km}^{2}$ (black bars of the last bin of the lower part of Fig. 4c). Figure 4b shows the 20y-mean[90th] and the associated 20y-mean[99th] below (Fig. 4d). The same logic should be applied for reading Figs. 6 and 7.

Figure 4a shows that the EURO-CORDEX simulations have more 20-year events of small-to-medium size, when compared to the ERA5 results, which is counterbalanced by fewer of the largest-sized events. One plausible explanation for the shift of large-size events toward small-to-medium size events is that the EURO-CORDEX simulations have a finer grid mesh, providing a smaller scale information to the interpolated grid when compared to ERA5. It would then be expected that smaller system size would be more frequent in those simulations, reducing the numbers of large-size events. The large inter-model spread from small-to-medium bin size is partly an artefact of the relatively small number of events in this section of the distribution, while at the same time the different models may have different capacity of representing small intense systems. It is worth mentioning that one largesize event is not necessarily compensated by one small-tomedium size event but rather several.

In general, Fig. 4 shows that the hindcast simulations and ERA5 are having a similar size distribution. Similar comments could be made for the historical simulations (see Fig. S3), indicating that there are no major discepancies in the simulated precipitation within the domain among RCMs driven by GCMs and when driven by re-analysis on the boundaries. This corroborates the interpretation that at least part of the ERA5 result is due to the coarser horizontal resolution compared to that of the RCMs.

Figure S1 shows the EURO-CORDEX 20y-size[90th] together with the 20y-size[90th] from ERA5 (on the ERA5

b)

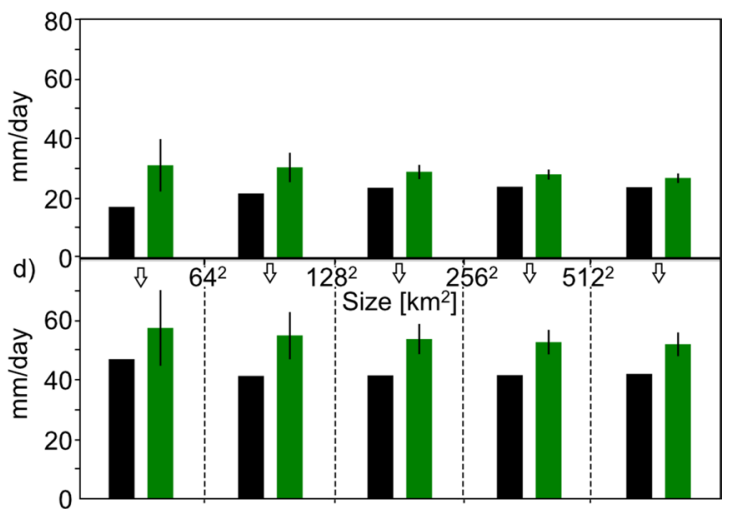

b shows the 20y-mean[90th]; panel c shows the 20y-size[99th] (note that the inter-member spread is small and then is not apparent because of the non-linear $y$-axis scale); panel d shows the 20y-mean[99th] 

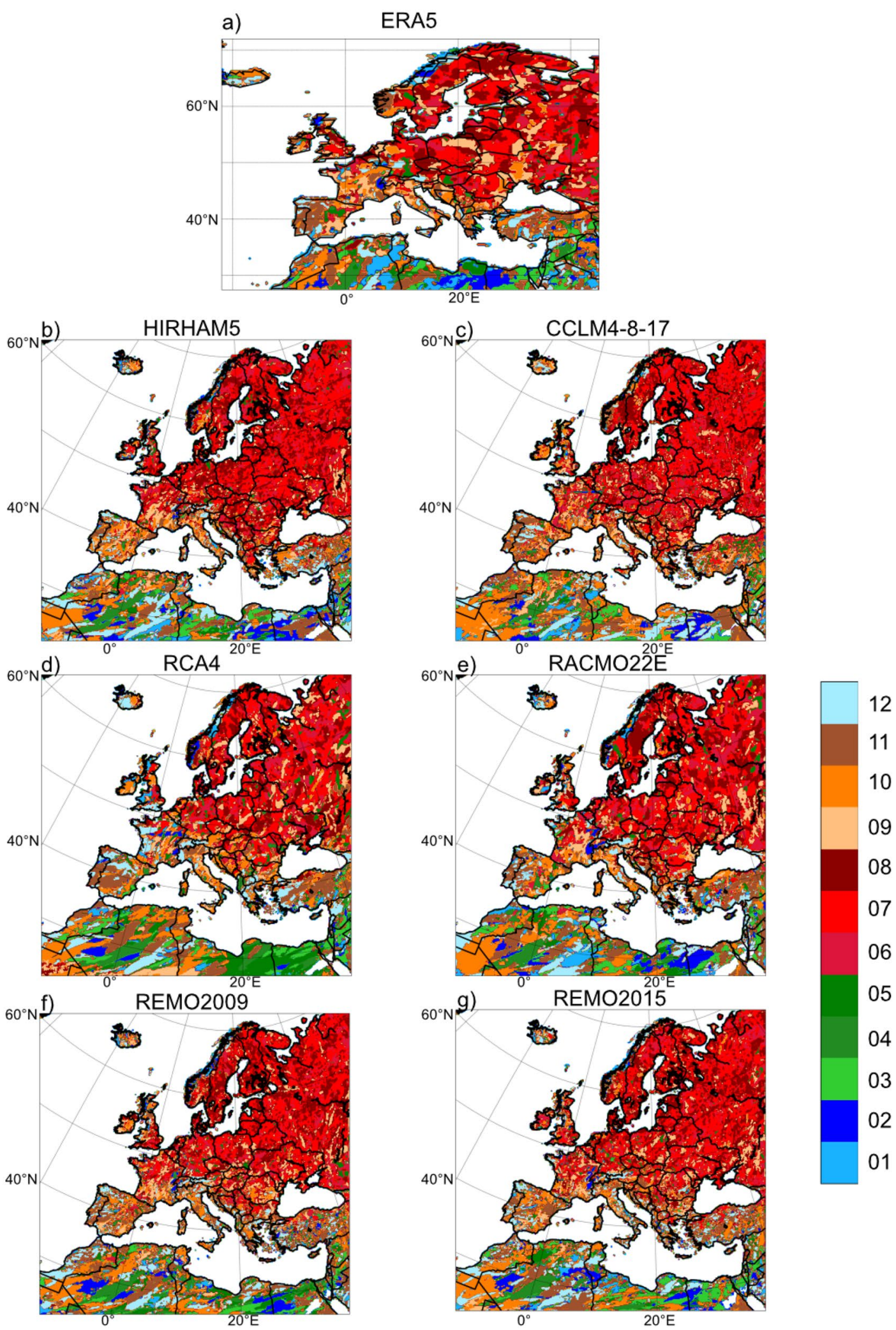

Fig. 5 The month of the year when the 20-years extreme precipitation has occurred for ERA5 (a) and the hindcast simulations (b-g) both on their original grid for the reference period of 1986-2005 
Fig. 6 Climate changes results over the whole EURO-CORDEX domains and sub-regions for the $1{ }^{\circ} \mathrm{C}$ (green), $2{ }^{\circ} \mathrm{C}$ (blue) and the $3{ }^{\circ} \mathrm{C}$ (red): panels a shows the changes in number of events of 20y-size[90th]; panels $\mathbf{c}$ shows the changes of 20y-mean[90th]; panels b shows the ratio between the different warming levels results with the historical results for the 20y-size[99th]; panels d shows the ratio between the different warming levels results with the historical results for the 20y-mean[99th]. The boxplots of the members inter-quantile range are defined by the 25 th percentile and the 75th percentile, the two wiskers show the 5th and the 95th, respectively, and dots show the outliers

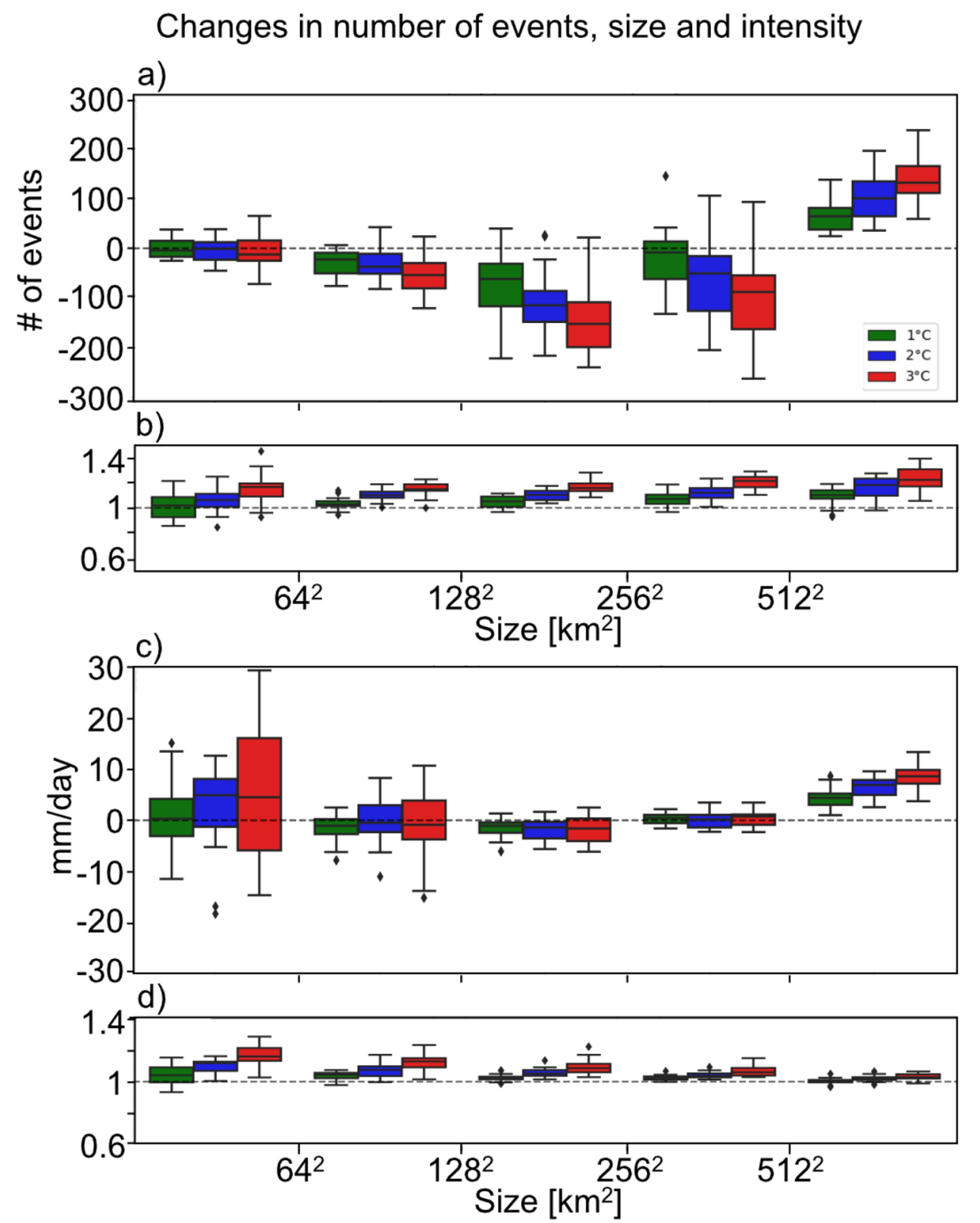

grid, Hindcast results on their original grid are shown in Fig. S2). Overall, ERA5 (Fig. S1a) has more large-size systems.

\subsection{Seasonality}

Figure 5 shows that seasonality of 20y-size extreme events differ depending on the regions for the reference period of 1986-2005. For ERA5 and all CORDEX simulations, extreme precipitation in the North-Eastern part (for example Central-Europe, the Alps and Eastern Europe as defined in Fig. 1) of the domain has a strong tendency to occur during summer. The rest of the domain is split between the 3 other seasons. Those results are in agreement with Marelle et al.
(2018) using CMIP5 models and with the historical simulations (not shown).

\section{Climate changes}

\subsection{Change in size and the total system average precipitation}

Figures 6 and 7 shows the changes (one member, one vote) in number of events and average intensity per size category for the $1{ }^{\circ} \mathrm{C}, 2{ }^{\circ} \mathrm{C}$ and the $3{ }^{\circ} \mathrm{C}$ warming levels (shown in green, blue and red, respectively) for the whole domain (Fig. 6) and the sub-regions (Fig. 7). 

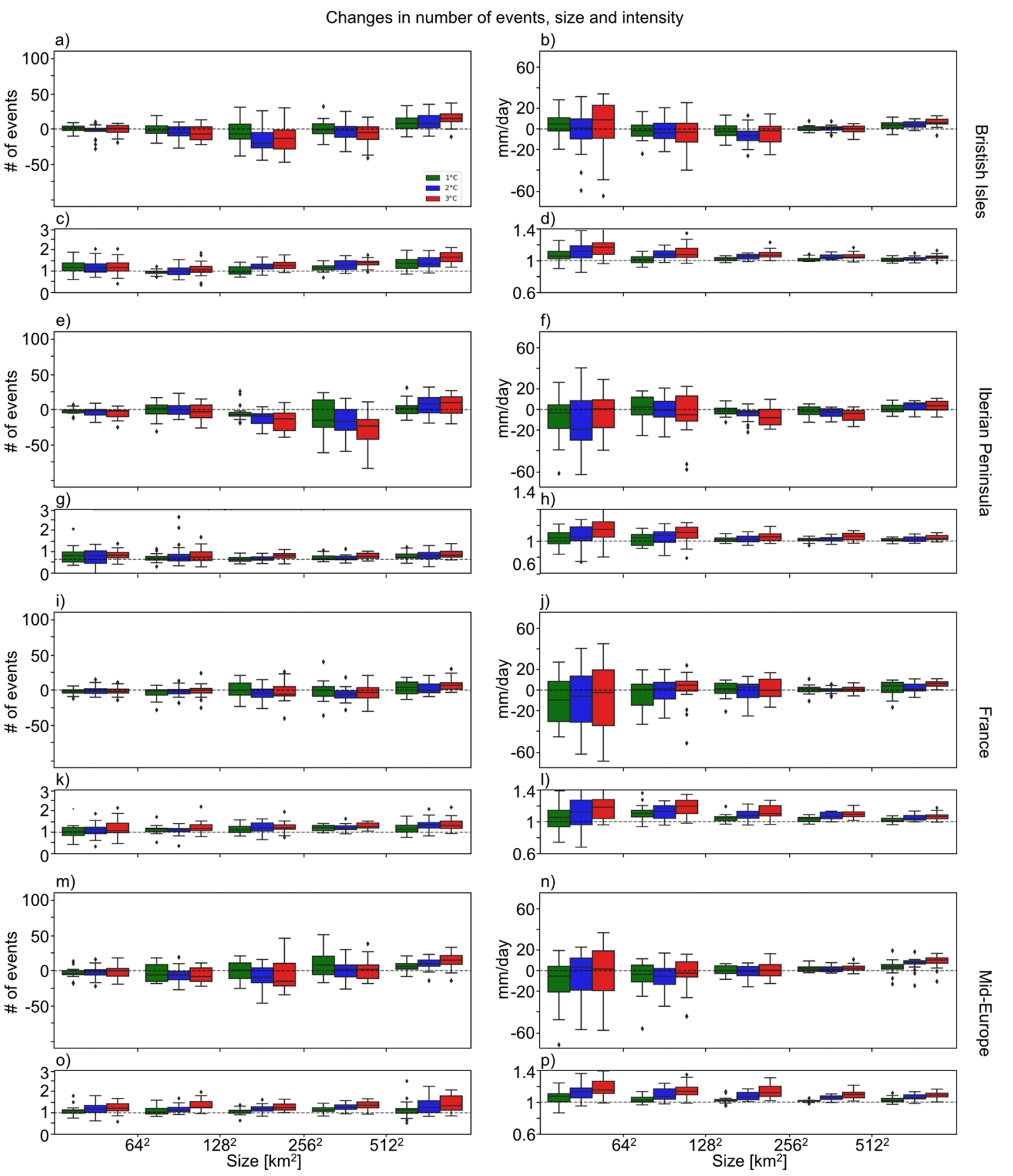

Fig. 7 Climate changes results over sub-regions for the $1{ }^{\circ} \mathrm{C}$ (green), $2{ }^{\circ} \mathrm{C}$ (blue) and the $3{ }^{\circ} \mathrm{C}$ (red): panels a, e, i, m, q, u, y, cc, gg show the changes in number of events of 20y-size[90th]; panels $\mathbf{b}, \mathbf{f}, \mathbf{j}, \mathbf{n}$, $\mathbf{r}, \mathbf{v}, \mathbf{z}, \mathbf{d d}, \mathbf{h h}$ show the changes of 20y-mean[90th]; panels $\mathbf{c}, \mathbf{g}, \mathbf{k}$, $\mathbf{o}, \mathbf{s}, \mathbf{w}, \mathbf{a a}, \mathbf{e e}, \mathbf{i i}$ show the ratio between the different warming levels

For the sake of clarification, here, we give an example of how to read the change in number of the large event $\left(>512^{2} \mathrm{~km}^{2}\right)$ and the associated changes 20y-size[99th] under a warmer conditions for the whole EURO-CORDEX domain. For this, one can look at the last bin of Fig. 6 a results and the historical results for the 20y-size[99th]; panels $\mathbf{d}, \mathbf{h}, \mathbf{l}$, $\mathbf{p}, \mathbf{t}, \mathbf{x}, \mathbf{b b}, \mathbf{f f}, \mathbf{j j}$ show the ratio between the different warming levels results and the historical results for the 20y-mean[99th]. The boxplots of the members inter-quantile range are defined by the 25 th percentile and the 75th percentile, the two wiskers show the 5th and the 95th, respectively, and dots show the outliers

which shows an increase in numbers of large events as the climate warms (for example, the 50th percentile shows a increase of $\approx 125$ events for the $3{ }^{\circ} \mathrm{C}$ level). Directly below (Fig. 6b) in the same bin (i.e. $>512^{2} \mathrm{~km}^{2}$ ) the ratio of the different warming level results with respect to the historical 

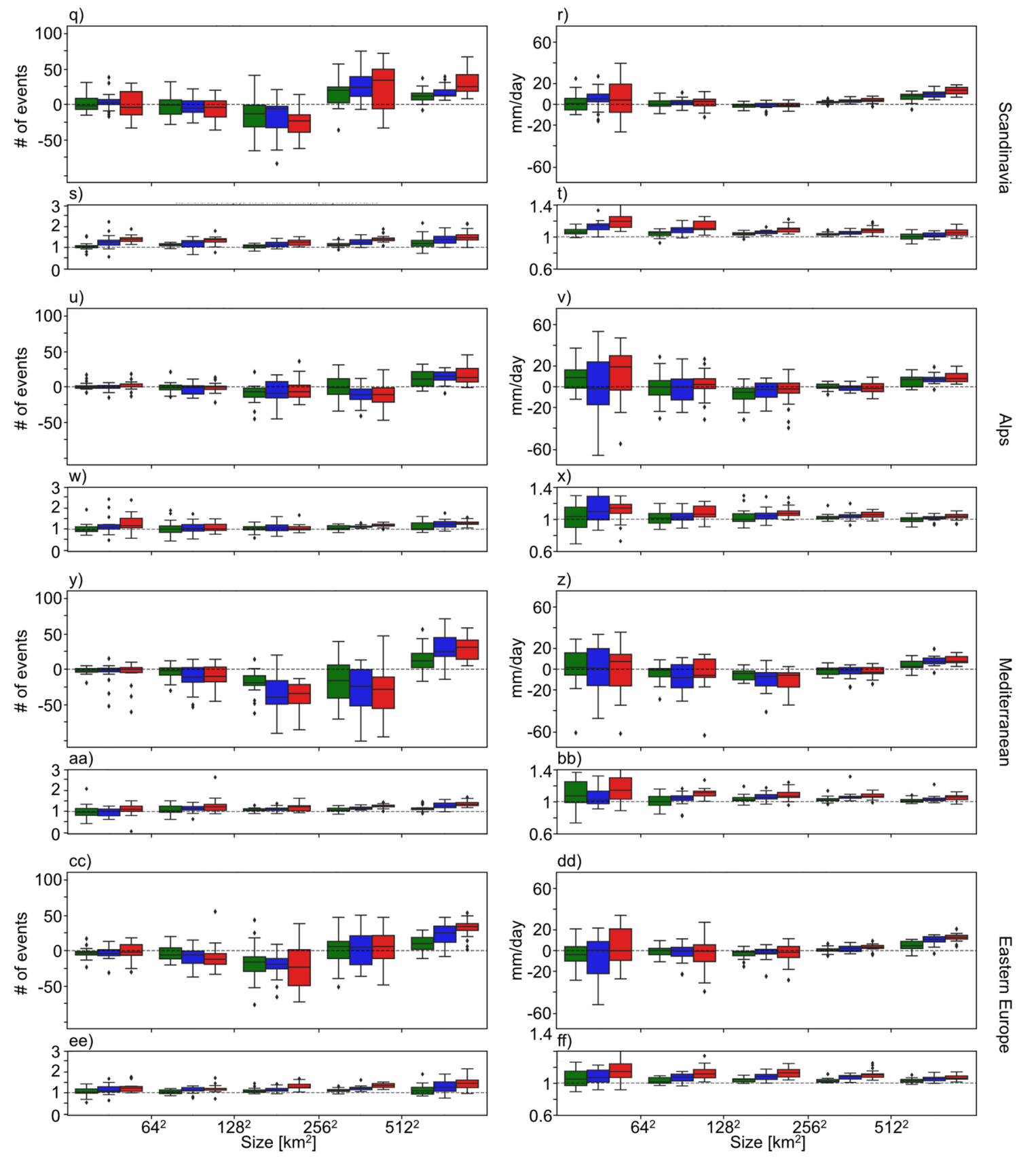

Fig. 7 (continued)

results for 20y-size[99th] is shown (for example, the 50th percentile shows a ratio of $\approx 1.2$ for the $3{ }^{\circ} \mathrm{C}$ level)

Figure 6a shows that over the whole EURO-CORDEX domain, the number of large size systems is increasing at the expense of the smaller-to-medium size systems while the 20y-size[99th] (Fig. 6b) is increasing for all bin sizes, as the climate warms. The 20y-mean[90th] (Fig. 6c) is increasing as climate warms for the larger systems. The 20y-mean[99th] (Fig. 6d) becomes more intense for almost all bin sizes. Figure 6a-d give an overview of the whole domain, however regional differences are noticed.

For each sub-region, there is an increase in number of large systems of 20y-size [90th] at the expense of the number of small- to medium-size systems, less so over France (Fig. 7i) and Mid-Europe (Fig. 7m). All subregions show an increase of the 20y-size[99th]. In other words, the overall system-size will tend to get bigger and their more intense core (i.e. 20y-size[99th]) expands. These results show that systems related to the 20 -years maximum 
precipitation will get bigger and have a larger intense core as climate warms.

The results for 20y-mean[90th] for the different subregions (Fig. 7b, f, j, n, r, v, z, dd) also suggest important changes as the climate is warming. As discussed for the whole EURO-CORDEX domain (Fig. 6b), the results for the sub-regions also indicate an increase in 20y-mean[90th] for the larger-sized systems in all subregions. Although the medium-size systems show small decreases in the 20y-mean[90th] for the British Isles, the Iberian Peninsula and Mediterranean (Fig. 7b, f, and z, respectively), other subregions do not show a clear pattern in this size range.

In the small-sized systems $\left(<128^{2} \mathrm{~km}^{2}\right)$, no clear pattern is identified for $20 y-m e a n[90 t h]$. In fact, the intermember spread is quite large, reflecting how models struggle representing smaller systems. For all size-ranges, the $20 \mathrm{y}$-mean[99th] is increasing for all different warming levels. In summary, these results suggest that the precipitation systems leading to an event producing a 20 -year precipitation extreme will become larger and more intense as temperature increases for the entire domain and in all subregions. The hindcast and the historical simulations have also been compared as it was done in Fig. 4 (see Fig. S3) and no major differences were found neither in the seasonality which suggests that the GCM has only a small, indirect or no impact at all on the size of the event produced by the RCM.

\subsection{Change in seasonality of extreme precipitation}

In this section, the seasonality of the 20 -years extreme precipitation is investigated for each warming level period. Figure S4 shows the density plot of the date of occurrence for the identified 20-years extreme events where all the members were bundled together for the four different periods. We see in Fig. S4i that occurrence is overall more frequent in summer over the whole EURO-CORDEX domain. However, Fig. S4a-h show that seasonality is different over all sub-regions while also not showing any significant changes in the seasonality as climate warms. Those results should be interpreted with caution, since changes in seasonality might still be apparent for second and third order ranked maximum precipitation, which is out of the scope of this study. This latter result is not in line with the findings of Marelle et al. (2018), and is most likely related to the fact that they used annual extreme precipitation instead of 20 -years extreme precipitation in their studies.

\section{Conclusion and discussion}

Here, we have investigated the changes in size of contiguous precipitation systems related to 20 years most extreme precipitation for different different warming levels using daily precipitation dataset from EURO-CORDEX. Our sanity check shows that the size distribution inferred from ERA5 was much alike from the size distribution inferred from the reanalysis driven simulations. However, some differences are also noted which are likely due to differences in grid-mesh size between the ERA5 dataset and the EURO-CORDEX models. The simulated results for the seasonality and the location of the 20y-size also seem to be in line with ERA5.

No large differences were found between the reanalysis driven simulations and the historical GCM driven simulations. This is suggesting that the choice of GCM has a small or no impact on the simulated size of an event, seasonality or location of the size of system related to extreme precipitation. In other words, this is indicating that the size distribution and intensity spectrum in this European case are due to the RCM physical parameterizations rather than provided by information advected over the boundaries.

We have demonstrated that systems associated with the 20-year extreme precipitation events will become larger and more intense with global warming for the entire domain as well as for various sub-regions analysed. This is more pronounced for the most intensive core of the precipitation system. Our analysis suggests that this could be resulting from larger availability of the overall energy and humidity. This investigation allows for a better understanding of the areal expansion of extreme precipitation related to climate change for the different warming levels of $1{ }^{\circ} \mathrm{C}, 2{ }^{\circ} \mathrm{C}$ and $3{ }^{\circ} \mathrm{C}$.

The results of this study should not be compared blindly to other studies since the adopted approaches and definitions are quite different. For example, we have studied the 20 -year most extreme events, while others have investigated whether all precipitation systems (Guinard et al. 2015) or only the most extreme by compiling all events using the tail of the distribution (Wasko et al. 2016), clearly forming very different approaches. In our study, we are stating that the most extreme events will become larger and more intense, but we do not, for example, inform about the overall behavior of less intense and more frequent events in warmer conditions.

Recently, many research groups have participated in the endeavor of producing convection-permitting climate simulations which should, in theory, bring some more detail of the landscape of extreme precipitation and its relationship to an increase of the global temperature. It is to be expected that mechanisms leading to the most extreme precipitation are better represented in those models. Despite the large computing cost and archive needed, more studies should be focusing on more characteristics of extreme precipitation 
including the consideration of the size of the events. We have shown in this study that the relationship to the size of extreme precipitation event with the average global warming is complex.

\section{Appendix: Selection of the Threshold}

There are at least 3 ways that one could think of to delineate a geographical area related to an extreme event while using a daily precipitation dataset. We could use:

1. The same hard threshold for all datasets, e.g. $10 \mathrm{~mm} /$ day.

2. An internally calibrated precipitation threshold for each member defined by the grid-point temporal distribution of the precipitation.

3. An internally calibrated precipitation threshold for each member defined by the spatial distribution of precipitation. a)

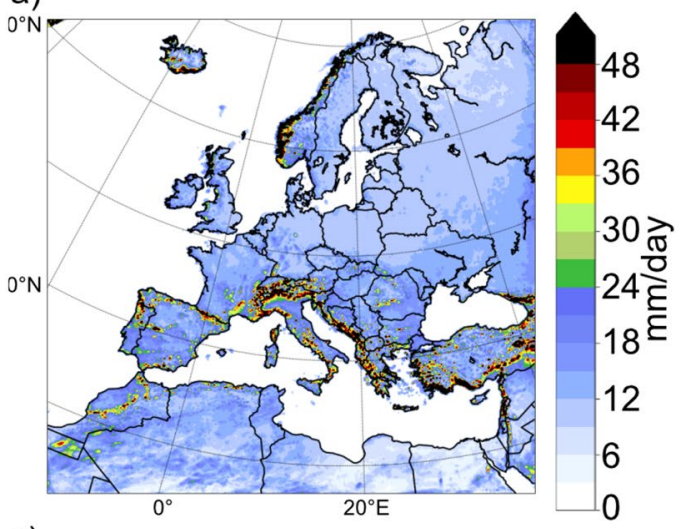

c)

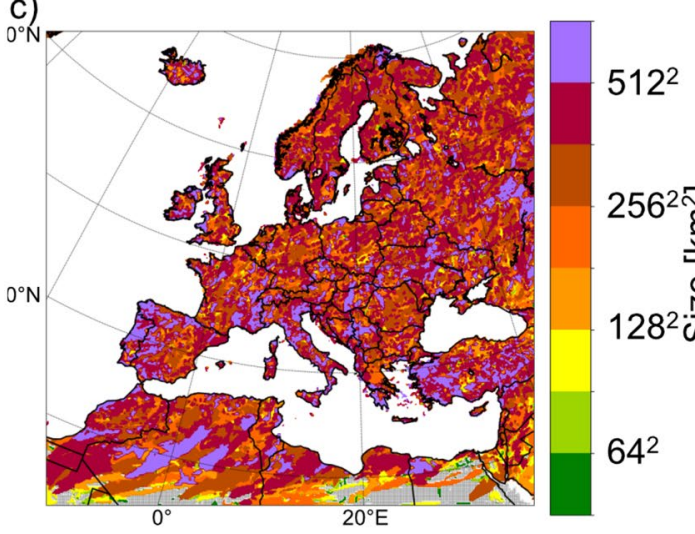

b)

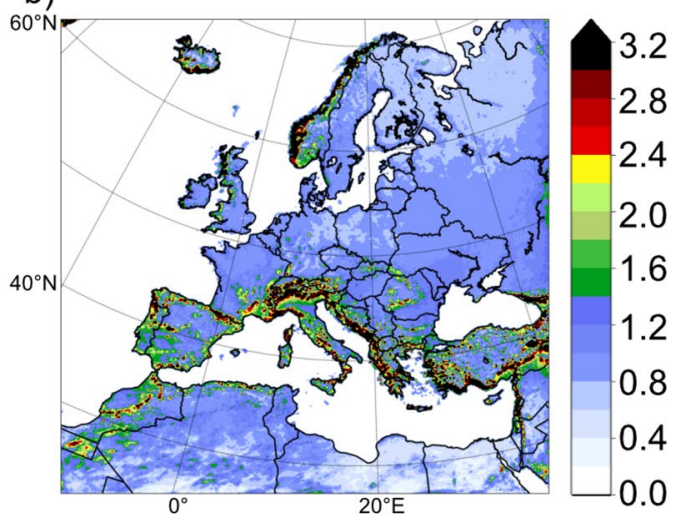

d)

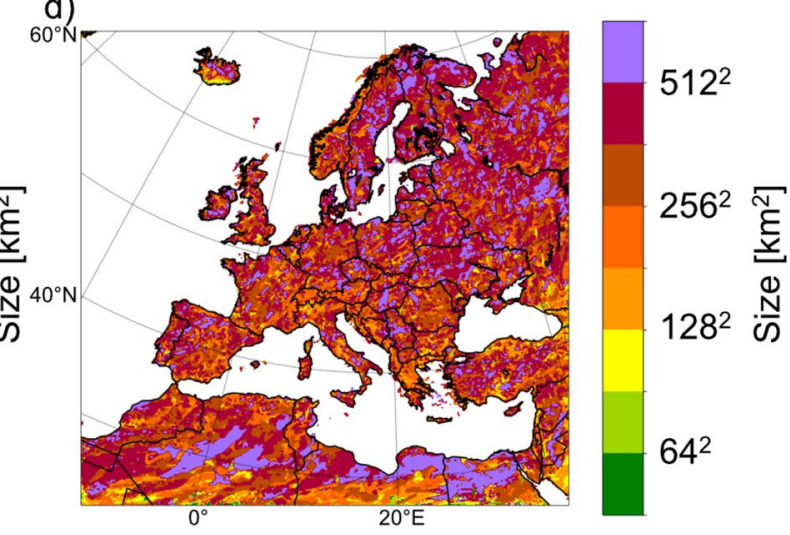

The first point is not suitable for model intercomparison or for climate change signals, as each model has its own precipitation climate, which means that some models could be dry, other wet and applying a hard threshold will definitely have an impact on the overall precipitation distribution when compared across all models.

In order to compare results from several models, an internally calibrated precipitation threshold is more appropriate, we argue. To do so, we have considered the two other approaches. The second of these approaches was discarded for the following reason. From Fig. 8a and b, it can be seen that some regions have a very large 90th percentile value when using the local percentile, which may be quite localized and not representing the neighboring regions at all. This means that if the local percentile is used to delineate the spatial extent of a system related to extreme precipitation, the size will be artificially small due to a too high value of the local 90th. Indeed, in Fig. 8d, it can be seen for some regions that the $20 \mathrm{y}$-size is smaller if using the local percentile (for example most of the Alps, Iceland, Western coast of Norway, every point where the ratio presented in Fig. $8 \mathrm{~b}$ 
is large). Those smaller 20y-sizes would be artefacts of the usage of the local percentile.

So, the main concern about choosing this approach is that for certain regions, such as in the Alps for example, this method will result in very small systems, not reflecting on the tendency for such events to form under general unstable conditions often affecting a wider region than depicted by a single grid point. For example, as depicted by Fig. 8, the a)

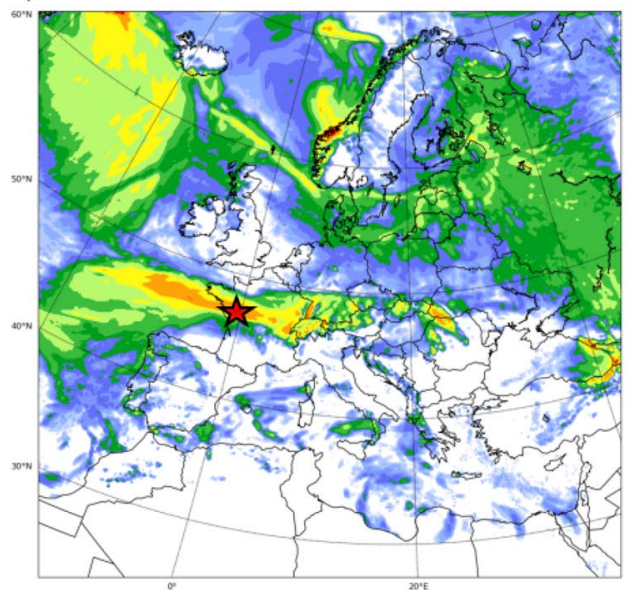

c)

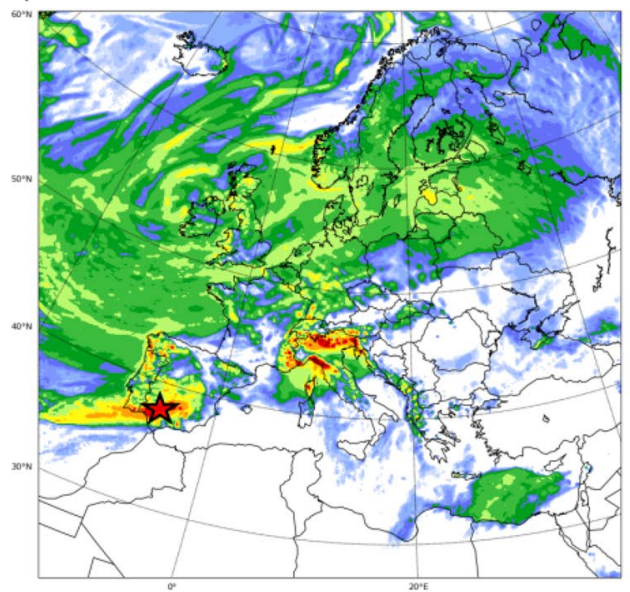

e)

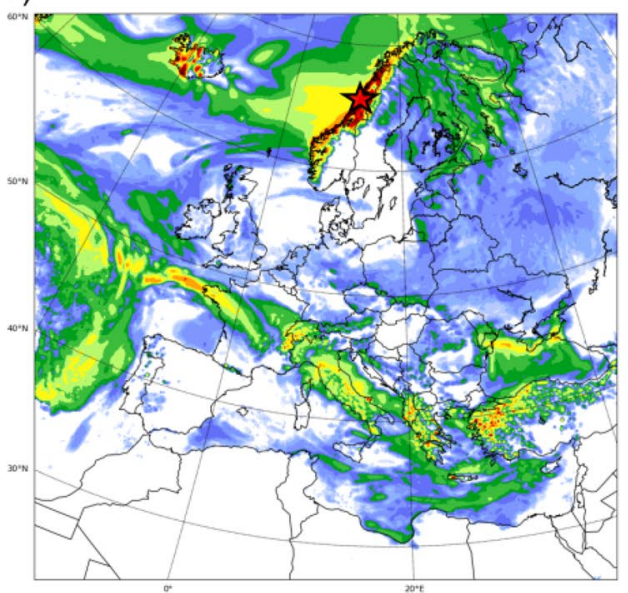

b)

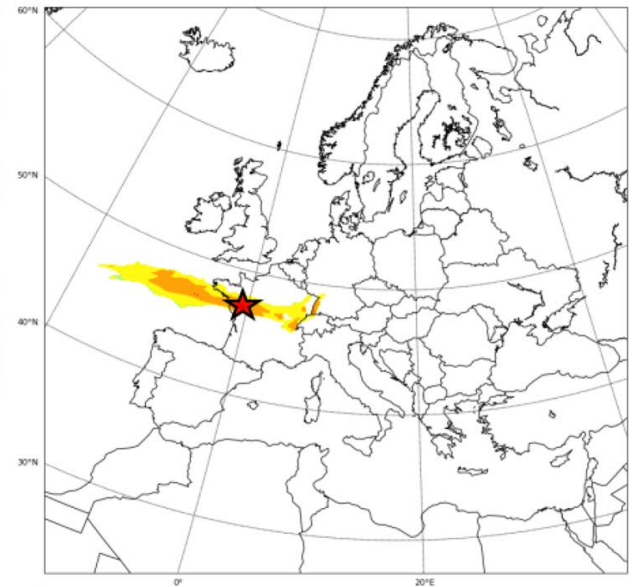

d)

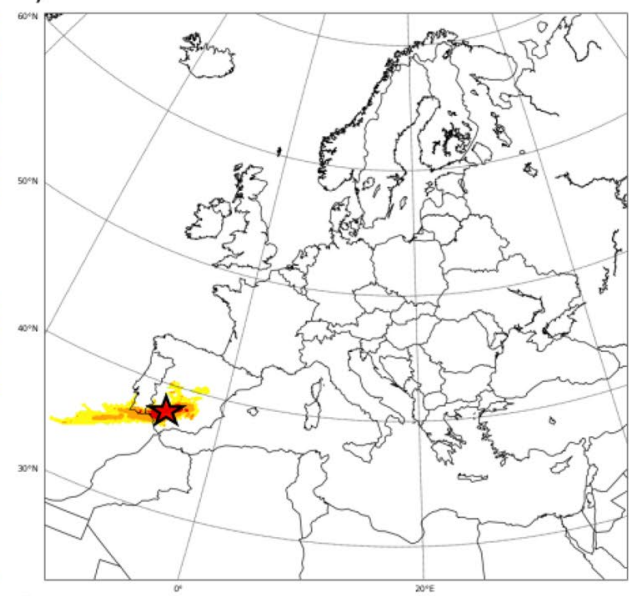

f)

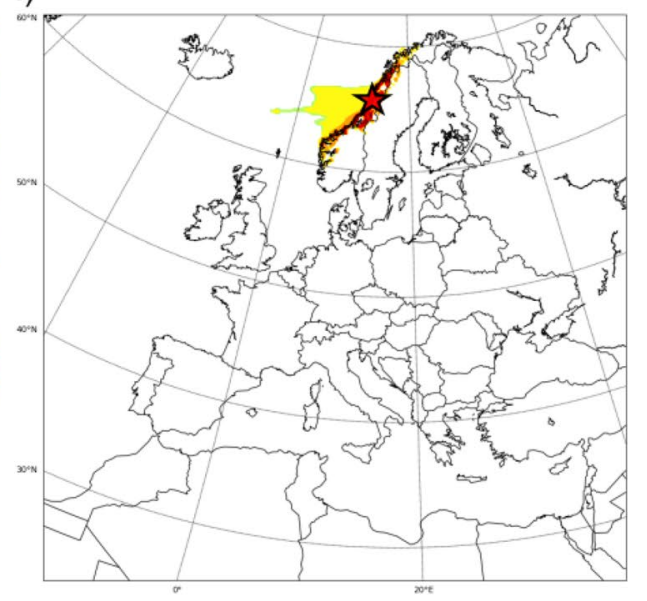

128

32

8

2 है

0.5

\subsection{5}

Fig. 9 Examples of daily precipitation maps (first column) and the impacted area delineated by the threshold used (second column) related to a particular grid point (shown by the red star) with a 20-year extreme precipitation for France (first row), Spain (second row) and Norway (third row) 
grid point's 90th percentile appear to be quite different, with some regions receiving almost $150 \mathrm{~mm} /$ day at some grid points. In the example shown in Fig. 3a of the manuscript, for the selected grid point (Lat:42.33 ${ }^{\circ}$; Lon: $18.89^{\circ}$ ), the 90th percentile at this location is $101 \mathrm{~mm} /$ day. Using such a large value as a threshold to delineate the simulated area shown in Fig. 3a would not be representative of the overall coherent precipitation pattern shown in the example for those specific $24 \mathrm{~h}$.

In order to demonstrate how the third (and our selected approach) behaves for different regions, we selected a few examples shown in Fig. 9 (e.g. for France (Fig. 9a, b), Spain (Fig. 9c, d), and Norway (Fig. 9e, f)). We argue that the system delineated by our threshold makes physical sense. If the grid point 90th percentile was chosen as a threshold, then the area under influence would have been quite different and small. For example, for each of the selected grid point (red stars) the grid point 90th percentile is 11, 32 and $39 \mathrm{~mm} /$ day for Fig. 9a-f, respectively. One sees that while little effect would have been noted for the selected grid point located in France (Fig. 9a, b), the impact on the associated area for Spain and Scandinavia would have been reduced considerably.

Supplementary Information The online version contains supplementary material available at https://doi.org/10.1007/s00382-021-05998-0.

Acknowledgements We acknowledge the World Climate Research Programme's CORDEX project for its role in making available the WCRP CORDEX multi-model data set, and we thank the climate modeling groups for producing and making available their model outputs. D.M. and J.H.C acknowledge funding by the European Union under the Horizon 2020 project EUCP (grant agreement 776613). T. O. was supported by the Scientific and Technological Research Council of Turkey (TUBITAK) under the programme TUBITAK 2219 - International Postdoctoral Research Fellowship.

\section{Declarations}

Conflict of interest The authors declare that they have no conflict of interest.

Open Access This article is licensed under a Creative Commons Attribution 4.0 International License, which permits use, sharing, adaptation, distribution and reproduction in any medium or format, as long as you give appropriate credit to the original author(s) and the source, provide a link to the Creative Commons licence, and indicate if changes were made. The images or other third party material in this article are included in the article's Creative Commons licence, unless indicated otherwise in a credit line to the material. If material is not included in the article's Creative Commons licence and your intended use is not permitted by statutory regulation or exceeds the permitted use, you will need to obtain permission directly from the copyright holder. To view a copy of this licence, visit http://creativecommons.org/licenses/by/4.0/.

\section{References}

Ahern M, Kovats RS, Wilkinson P, Few R, Matthies F (2005) Global health impacts of floods: epidemiologic evidence. Epidemiol Rev 27(1):36-46

Benestad RE (2018) Implications of a decrease in the precipitation area for the past and the future. Environ Res Lett 13(4):044022

Berg P, Moseley C, Haerter JO (2013) Strong increase in convective precipitation in response to higher temperatures. Nat Geosci 6(3):181-185

Brönnimann S, Rajczak J, Fischer EM, Raible C, Rohrer M, Schär C (2018) Changing seasonality of moderate and extreme precipitation events in the alps. Nat Hazards Earth Syst Sci 18(7):2047-2056

Chan SC, Kahana R, Kendon EJ, Fowler HJ (2018) Projected changes in extreme precipitation over SScotland and northern England using a high-resolution regional climate model. Clim Dyn 51(9-10):3559-3577

Chang W, Stein ML, Wang J, Kotamarthi VR, Moyer EJ (2016) Changes in spatiotemporal precipitation patterns in changing climate conditions. J Clim 29(23):8355-8376

Christensen JH, Christensen OB (2003) Severe summertime flooding in Europe. Nature 421(6925):805-806

Christensen JH, Christensen OB (2007) A summary of the PRUDENCE model projections of changes in European climate by the end of this century. Clim Change 81(1):7-30

Cornes RC, van der Schrier G, van den Besselaar EJM, Jones PD (2018) An ensemble version of the e-obs temperature and precipitation data sets. J Geophys Res-Atmos 123(17):9391-9409

Frei C, Schär C, Lüthi D, Davies HC (1998) Heavy precipitation processes in a warmer climate. Geophys Res Lett 25(9):1431-1434

Guinard K, Mailhot A, Caya D (2015) Projected changes in characteristics of precipitation spatial structures over North America. Int J Climatol 35(4):596-612

Hallegatte S, Green C, Nicholls RJ, Corfee-Morlot J (2013) Future flood losses in major coastal cities. Nat Clim Change 3(9):802-806

Hersbach H, Bell B, Berrisford P, Hirahara S, Horányi A, Muñoz-Sabater J, Nicolas J, Peubey C, Radu R, Schepers D (2020) The era5 global reanalysis. Q J Roy Meteorol Soc 146(730):1999-2049

Jacob D, Petersen J, Eggert B, Alias A, Christensen OB, Bouwer LM, Braun A, Colette A, Déqué M, Georgievski G (2014) EUROCORDEX: new high-resolution climate change projections for European impact research. Reg Environ Change 14(2):563-578

Knapp AK, Beier C, Briske DD, Classen AT, Luo Y, Reichstein M, Smith MD, Smith SD, Bell JE, Fay PA (2008) Consequences of more extreme precipitation regimes for terrestrial ecosystems. BioScience 58(9):811-821

Liu AQ, Mooney C, Szeto K, Thériault JM, Kochtubajda B, Stewart RE, Boodoo S, Goodson R, Li Y, Pomeroy J (2016) The June 2013 alberta catastrophic flooding event: part 1-climatological aspects and hydrometeorological features. Hydrol Process 30(26):4899-4916

Lochbihler K, Lenderink G, Siebesma AP (2017) The spatial extent of rainfall events and its relation to precipitation scaling. Geophys Res Let 44(16):8629-8636

Marelle L, Myhre G, Hodnebrog O, Sillmann J, Samset BH (2018) The changing seasonality of extreme daily precipitation. Geophys Res Lett 45(20): 11-352

Masson-Delmotte V, Zhai P, Pörtner HO, Roberts D, Skea J, Shukla PR, Pirani A, Moufouma-Okia W, Péan C, Pidcock R (2018) Global warming of $1.5^{\circ} \mathrm{C}$ : an IPCC special report on the impacts of global warming of $1.5^{\circ} \mathrm{C}$ above pre-industrial levels and related global greenhouse gas emission pathways, in the context of strengthening the global response to the threat of 
climate change, sustainable development, and efforts to eradicate poverty. WMO, Geneva

Moss RH, Edmonds JA, Hibbard KA, Manning MR, Rose SK, Van Vuuren DP, Carter TR, Emori S, Kainuma M, Kram T (2010) The next generation of scenarios for climate change research and assessment. Nature 463(7282):747-756

Nogueira M (2020) Inter-comparison of era-5, era-interim and QPCP rainfall over the last 40 years: process-based analysis of systematic and random differences. J Hydrol 583:124632

O'Gorman PA, Schneider T (2009) The physical basis for increases in precipitation extremes in simulations of 21 st-century climate change. P Natl Acad Sci 106(35):14773-14777

Prein AF, Langhans W, Fosser G, Ferrone A, Ban N, Goergen K, Keller M, Tölle M, Gutjahr O, Feser F (2015) A review on regional convection-permitting climate modeling: demonstrations, prospects, and challenges. Rev Geophys. https://doi.org/ 10.1002/2014RG000475

Prein AF, Liu C, Ikeda K, Trier SB, Rasmussen RM, Holland GJ, Clark MP (2017a) Increased rainfall volume from future convective storms in the US. Nat Clim Change 7(12):880-884

Prein AF, Rasmussen RM, Ikeda K, Liu C, Clark MP, Holland GJ (2017b) The future intensification of hourly precipitation extremes. Nat Clim Change 7(1):48-52

Púčik T, Groenemeijer P, Rädler AT, Tijssen L, Nikulin G, Prein AF, van Meijgaard E, Fealy R, Jacob D, Teichmann C (2017) Future changes in European severe convection environments in a regional climate model ensemble. J Clim 30(17):6771-6794

Rajczak J, Schär C (2017) Projections of future precipitation extremes over Europe: a multimodel assessment of climate simulations. J Geophys Res-Atmos 122(20):10-773

Rivoire P, Martius O, Naveau P (2021) A comparison of moderate and extreme era-5 daily precipitation with two observational data sets. ESSOAR. https://doi.org/10.1029/2020EA001633
Scaff L, Prein AF, Li Y, Liu C, Rasmussen R, Ikeda K (2019) Simulating the convective precipitation diurnal cycle in north Americas current and future climate. Clim Dyn 55:369-382

Simmons AS, Uppala DD, Kobayashi S (2006) Era-interim : new ecmwf reanalysis products from 1989 onwards. ECMWF Newsl 110:25-36

Touma D, Michalak AM, Swain DL, Diffenbaugh NS (2018) Characterizing the spatial scales of extreme daily precipitation in the United States. J Clim 31(19):8023-8037

Tramblay Y, Somot S (2018) Future evolution of extreme precipitation in the mediterranean. Clim Change 151(2):289-302

Trenberth KE, Dai A, Rasmussen RM, Parsons DB (2003) The changing character of precipitation. Bull Am Meteorol Soc 84(9):1205-1218

Wasko C, Sharma A, Westra S (2016) Reduced spatial extent of extreme storms at higher temperatures. Geophys Res Let 43(8):4026-4032

Westra S, Fowler HJ, Evans JP, Alexander LV, Berg P, Johnson F, Kendon EJ, Lenderink G, Roberts NM (2014) Future changes to the intensity and frequency of short-duration extreme rainfall. Rev Geophys 52(3):522-555

Woetmann NA (2011) Dowpour in copenhagen on july2, 2011. Vejret 128:12-22 (in danish)

Publisher's Note Springer Nature remains neutral with regard to jurisdictional claims in published maps and institutional affiliations. 